\title{
Teatro en la provincia argentina de Corrientes: sus historias, devenires y actualidad (1era. Parte)
}

\author{
Malala González \\ Universidad de Buenos Aires, Argentina \\ malalagonzalez22@gmail.com
}

Fecha de recepción: 22/06/2020. Fecha de aceptación: 26/08/2020

\begin{abstract}
Resumen
Este trabajo de investigación se propone estudiar la actividad teatral en la provincia argentina de Corrientes contemplando desde sus orígenes pre-coloniales hasta su devenir en la actualidad reciente (2010). Teniendo en cuenta diversas etapas-cronológicas y estéticas- intentaremos sintetizar y focalizar sobre algunos momentos y aspectos en los que el sistema teatral correntino ha tomado mayor vigor y relevancia en su historia. Para ello abordaremos la formación y trayectoria de numerosos grupos, los y las referentes de diversas épocas, los espacios teatrales de la provincia y la convivencia con el carnaval, entre otros rasgos capaces de reflejar su derrotero escénico.
\end{abstract}

Palabras clave: Teatro argentino, Corrientes, Historia, Actividad teatral

\section{Theatre in the Argentine Province of Corrientes: its History, Trajectories and Present (Part 1)}

\begin{abstract}
This work aims to study theatrical activity in the Argentine province of Corrientes, from its pre-colonial origins until its recent development (2010). Taking into account different chronological and aesthetic periods, we will focus on some of the most relevant moments and aspects in its history. In order to do so, we will address the formation and trajectory of numerous groups, the referents of different times, the theatrical spaces and the coexistence with the carnival, amongst other viable approaches which can contribute to reflect and synthesize the transformations of Corrientes theatre system.
\end{abstract}

Key words: Argentine Theatre, Corrientes, History, Theatrical Activity 


\section{Introducción}

Este trabajo de investigación se propone historizar la actividad teatral en la provincia argentina de Corrientes desde sus orígenes pre-coloniales hasta la actualidad reciente (2010). Teniendo en cuenta diversas etapas -cronológicas y estéticas- intentaremos sintetizar y focalizar sobre algunos momentos y aspectos en los que -creemos y deducimos- el sistema teatral correntino ha tomado mayor vigor y relevancia en su historia.

Asimismo, corresponde aclarar que esta investigación ha sido emprendida a partir de un viaje hacia la provincia mesopotámica durante octubre de 2009 -como parte de un proyecto que dirigiera el Dr. Osvaldo Pellettieri sobre el teatro en las provincias dentro del Grupo de Estudios de Teatro Argentino e Iberoamericano (GETEA) que contó con el apoyo del Instituto Nacional del Teatro (INT)- y gracias al cual se han obtenido datos fundamentales para poder contar, de algún modo, parte de su historia teatral. Es por ello que a las consultas de archivos y material documental y paratextual de diferentes puestas en escena se sumó un trabajo de campo concreto que consistió en la realización de entrevistas a teatristas, investigadores/as, público y gestores/as del área cultural, quienes -al contar su propia experiencia como memoria y conocimiento local-nutrieron de manera esencial la información que se reúne en estas páginas. Mi agradecimiento a todos/as los/as correntinos/as que han compartido y permitido, desde sus palabras, esclarecer, conocer y disfrutar de sus anécdotas y diálogos parte de nuestro pasado y presente teatral. Gracias a Mauro Santamaría, Leyla (del INT), Dante Cena, Marcelo Daniel Fernández, Alejandro Barboza y todo su elenco, Susana Bernardi y Luigi Serradori, Ángel Quintela y María Esther Aguirre, Silvia Rivero, Karen De Micheli, Jorge Frete, Hilda Martínez Da Cundha, Isaac “Taka” Benítez, Marianela Iglesias, Vicky Mecca, Adriana Covalova, Alcides y Gabriel Romero, Leonardo Espíndola, Lorena Busciglio, Rosmarie y Alexis; Bernardo Alvarenga, Milton Rosés; Isidoro Levitsky y su mujer, José Ramírez, Eduardo Sívori, Betty Perotti, Familia González de Paso de los Libres, Estela Gómez, Gustavo Insaurralde, Carlos "Cacha” Trinidad, Mirta Bertone, Ramón Francisco Fernández y Hugo Fernández, Carlos Ginocchi, Dorita Ginocchi, Liliana Padín, Grisela Echavarría, Norma Romano, Sebastián Genes, Lito Zampar y a Horacio Carbone por cada entrevista brindada.

Así, partiendo de dichas entrevistas, pero fundamentalmente guiada por una bibliografía clave como resultó el libro de Marcelo Daniel Fernández (quien también fuera entrevistado durante dicha estadía) sobre la historia de la actividad teatral en la provincia publicado por el INT, intentaré dar cuenta de cómo se ha desarrollado y consolidado la actividad en la provincia. Atendiendo a la conformación y trayectoria de diferentes artistas y grupos locales, y relevando acontecimientos socio-históricos puntuales, partiremos de la ciudad capital hacia algunas localidades del interior de la provincia.

De esta manera dividiremos el trabajo y material reunido en dos partes. En esta primera, desde un enfoque cronológico ordenador, estará organizado y segmentado en tres etapas: la sistematización del campo teatral (1880- 1970); la consolidación del campo y los cambios que introduce una figura como Dante Cena (1970-1990) y un último período a partir de la creación del Instituto Nacional del Teatro hasta la actualidad reciente (1990-2010). Y, finalmente, para cerrar esta parte de la investigación, abordaremos los espacios teatrales y aspectos relativos al público asistente en la ciudad Capital. Ahora bien, antes de detenernos en cada una de esas tres etapas, resulta menester realizar una breve contextualización provincial preliminar en torno a dos aspectos socio-culturales: el guaraní y el carnaval.

Corrientes se encuentra entre las provincias argentinas con mayor antigüedad desde su fundación colonial, la cual tuvo lugar el 3 de abril de 1588 a cargo de Don Juan 
Torres de Vera y Aragón. Pero, ciertamente, la ocupación de su territorio por pueblos originarios ha sido considerablemente anterior a ese período. Tierra de agricultura, caza y pesca habitada por diferentes tribus como los Caingangs (al Este); los Mocoretás (al Sudeste) y los Guaycurúes (al Oeste) y principalmente poblada por los Guaraníes (AAVV, 1990). Ubicados al Norte, sobre el Alto Paraná, esta comunidad predominante poseía una gran cultura festiva y creencias que, a partir de la colonización española fueron menguando. Sin embargo, luego de la conquista algunas de sus raíces y tradiciones no desaparecieron, al tiempo que lograron mezclarse y reformularse. Tal fue el caso de la lengua guaraní, herencia que los conectaba con la naturaleza de manera poética y primordial en su comunicación. Este rasgo lingüístico ha logrado pervivir hasta la actualidad en gran parte de las palabras que conforman el hablar coloquial actual de los/as correntinos/as que, además de haber constituido parte del vocabulario botánico y de fauna autóctonos, como también constituyente de nombres de lugares, alimentos y productos medicinales. Este bilingüismo guaraní-castellano resulta esencial en el paisaje (De París, 1988) y por ello, al mantener parte de una cultura heredada, las teatralidades propias del lugar no pueden serle indiferentes $y$, menos aún, ignorar esta característica auténticamente local. Como sostiene el investigador correntino Isaac "Taka" Benítez, el atender a esta lengua intrínseca sería una particularidad que "acorde con ese costado aborigen que nos habita" alude a una "regionalidad que no podemos eludir sin traicionarnos" (material cedido por su autor. Inédito).

Con la llegada de los españoles a la región se inició un período de intercambio y culturización totalmente diferente al precedente. Las tropas españolas contaron con el apoyo de cuatro órdenes religiosas -Jesuitas, Dominicos, Mercedarios y Franciscanos- encargadas de alfabetizar y misionar a la población. En la zona capitalina se instaló la Orden de los Jesuitas que durante el siglo XVII catequizó con una participación gubernamental, lo que produjo consecuentemente una hibridación entre los ritos paganos y el culto católico. Y, si la base de toda cultura se asienta "en lengua y religión" (De París, 1988), el escenario correntino supo combinar la cosmovisión indígena con el mestizaje cultural. A esta imbricación de oralidad y religión se sumaron los cultos a diferentes figuras, santos y gauchos, que dio lugar a nuevas celebraciones paganas y ortodoxas. Se pueden mencionar los cultos a la Virgen de Itatí, a San Baltasar y a San La Muerte y cultos a gauchos consagrados, entre ellos el Gauchito Gil, Gaucho Lega, Antonio María, el Gaucho Aparicio Altamirano y el Pombero (principalmente en toda la zona rural), muchos de ellos sostenidos hasta la actualidad.

Los Jesuitas encontraron en el teatro una enseñanza, como un método didáctico para evangelizar. Las primeras representaciones teatrales bajo su mandato datan del siglo XVI y XVII con dramas y pasajes musicales. Según recopila Marcelo D. Fernández, durante el siglo XVII, se registran actos teatrales los domingos por la tarde en la plaza del centro de la ciudad, los cuales, siendo dramas de carácter religioso, contaban alguna historia relativa a la Corona Española.

Por otro lado, la oralidad musical del idioma guaraní -de índole gutural- permite observar cómo la música fue un elemento permanente desde los orígenes que, junto con la danza estuvieron a la hora de todos los festejos compartidos socialmente. Ambas artes acompañaron la expresión corporal desde tiempos pre-coloniales.

La colonización también aparejó otra hibridación cultural a partir de otras etnias inmigrantes. Junto con los españoles llegaron centenares de esclavos traídos desde África por Portugal, los cuales fueron ubicados en el mismo estrato social que la población local preexistente. Estos esclavos también importaron su cultura a partir de la música y la danza y colaboraron en la formación de esta cultura correntina tan heterogénea. 
Ahora bien, el otro elemento constitutivo por destacar en esta breve contextualización, y que ha tenido gran importancia para la provincia desde sus orígenes, es el carnaval. Al estar en una zona de frontera, limítrofe y tripartita con Uruguay, Brasil y Paraguay, Corrientes ha logrado acuñar intercambios constantes con las culturas vecinas que se vieron reflejados en esta práctica artística. Desde los inicios, el carnaval ha sabido identificarse con la población correntina, permitiéndole una conexión inherente con su cultura ancestral. Ha ocupado, desde siempre, un lugar primordial dentro de las festividades populares, generando así una participación inclusiva de pertenencia a la comunidad en torno a su ritual. Expresión que ya pertenecía a los guaraníes, según los Jesuitas, que festejaban una vez al año durante seis días con bailes, música, máscaras, con cuerpos pintados, plumas y bebidas espirituosas. Todo ello comprometía una preparación minuciosa que aguardaban con ansias anualmente. De orden dionisíaco, esos cuerpos desbordados, en contacto con el mundo, en un tiempo otro al cotidiano, eran parte de la fiesta que traía consigo la posibilidad de homogenización entre estratos sociales, y en donde los sectores más bajos podían sentirse pares de otros más acomodados.

A mediados del siglo XIX, ciertos hábitos del festejo se consolidan y se tornan costumbre para prepararlo. Simultáneamente, aparecen algunos personajes característicos a partir del uso de disfraces empleados. En 1840, los bailes de máscaras eran muy comunes y los mismos fueron trasladados a los salones de los teatros (Leguiza, 2007:34). Y fue en 1881 cuando el Teatro Vera, sobre el cual volveremos más adelante, se convirtió en una de las sedes para el baile del gran festejo (Fernández, 2007). Así, a principio del siglo XX, se los llamó bailes de disfraz y fantasía (Leguiza, 2007: 132) o fiestas carnestolendas, al tiempo que comenzaban los concursos de reinas y premiaciones para los disfraces más bonitos. Con el tiempo, la diferenciación social fue cada vez más acentuada: aparecieron carruajes ostentosos correspondientes a la gente más pudiente. Sin embargo, poco a poco, la clase alta comenzó a alejarse de la celebración, lo que dio lugar a que la manifestación se tornase eminentemente popular. En la ciudad capital, aproximadamente en 1940, se produjo una traslación importante del carnaval hacia los barrios aledaños.

Recién en 1961 logra una modificación en su composición a partir de los concursos de comparsas. Esto, tal como sostiene Fernández (2007), fue lo que logró redefinir al carnaval correntino como puro arte en movimiento. Por un lado, se encontraba Copacabana, la comparsa más ligada a la oligarquía terrateniente, con una estética próxima a la danza y, por otro lado, estaba Araberá, comparsa ligada a la clase media ascendente, más afín al teatro (Fernández 2007:53). Durante aquel año se incorporó la música autóctona a las correspondientes coreografías, incluyendo una representación teatral denominada show de comparsa, al que arribaban luego del paseo por las calles urbanas.

Entonces, de algún modo, podemos decir que aquel fenómeno festivo realizado por los guaraníes, logró reinventarse y perdurar hasta la actualidad más allá de claras distancias estéticas, y modos de concebir la práctica. Hay quienes coinciden en que es en los barrios donde hoy continúa aquel espíritu de indiferenciación social y mezcla de clases, mientras que, en la ciudad capital, el evento se ha tornado de tinte más espectacular que participativo debido a la fuerte impronta comercial que fue adquiriendo paulatinamente. Aquí se observa que la legislación colaboró en la delimitación espacial celebratoria que consecuentemente resultó ser una marca divisoria por la colocación de tribunas para espectadores/as. Algo que, en algún sentido, menguó con aquella esencia de participación colectiva.

Convertido hoy en un verdadero espectáculo provisto, por un lado, de participantes y, por otro, de una platea con público, el carnaval en la provincia tiene un sello cultural 
propio de tamaña magnitud y participación. La necesidad de vivenciar esta fiesta una vez al año es algo que perdura en gran parte de la población, ocupando en la sociedad un lugar preferencial. Todos/as esperan con gran valor sentimental y pasional al carnaval, todos/as trabajan para él y todos/as lo festejan, ya sea bailando o mirando. Más adelante, retomaremos algunos aspectos de esta convivencia entre los festejos del carnaval y el sistema teatral propiamente dicho.

\section{Primera etapa teatral: desde 1880 hasta 1970}

Hacia mediados del siglo XIX y hasta las primeras décadas del siglo XX, la mayor parte de los espectáculos representados en Corrientes -tales como óperas, operetas o zarzuelas- eran extranjeros. Se trataba de compañías que viajaban por todo el país llevando sus producciones a diferentes escenarios. El Teatro Vera de la Capital-construido e inaugurado en 1861 y posteriormente reinaugurado en 1913- fue encargado de albergar a estas compañías junto con otros teatros oficiales ubicados en localidades interinas, como Monte Caseros (teatro edificado en 1928), Mercedes (teatro edificado en 1880) y Goya (teatro edificado en 1879). Estas arquitecturas construidas a la italiana, poseedoras de gran acústica, advierten un cierto gusto teatral ligado a espectáculos musicales y ballets propio de las clases más acomodadas y aristocráticas, encargadas de subvencionar las correspondientes edificaciones. Esto respondía a una preferencia refinada por el género lírico-dramático y en especial por repertorio dramático de autores españoles (Fernández, 2005).

A partir de los años 40, aparecen las primeras compañías filo-dramáticas o vocacionales oriundas de Corrientes. Este fenómeno no sólo tuvo su despertar en la capital provincial, sino que también apareció en otras localidades del interior. Según el registro de Fernández (2005), en 1944 se estrenó La enemiga de Darío Nicodemi, que dio origen a la conformación de la Compañía Correntina de Arte Escénico. Cinco años más tarde, esta misma obra también inauguró al grupo goyano Candilejas. Además, se observa la aparición de otros grupos vocacionales coyunturales como el Teatro Vocacional de Curuzú-Cuatiá y a la Agrupación Teatral Antorcha. Dentro de este panorama emergente de grupos locales destinados a desarrollar la actividad de manera vocacional hubo dos elencos capitalinos que marcaron tendencia: el Teatro Experimental Alborada -posteriormente conocido como Vocacional Corrientes-y el Círculo de la Juventud Israelita, posteriormente denominado Teatro Experimental Scholem Aleijem (T.E.S.A.).

El Teatro Experimental Alborada logró convertirse en una institución teatral que, fundada en 1947 como el grupo más antiguo del país, continúa en actividad hasta la actualidad. Edgar Romero Maciel, formado en Buenos Aires y a cargo de veintiuna obras estrenadas, fue su director fundador. Con apenas tres años de existencia, en 1950, fue consagrado en la final del Gran Certamen Nacional de Teatros Vocacionales y, en 1953, cambió de nombre por la actual denominación Teatro Vocacional Corrientes. Bajo el lema "actividad continua e ininterrumpida" enorgullece a sus integrantes y a la sociedad correntina en general.

Con una metodología de trabajo de mesa que desprendía una minuciosa dirección sobre el cómo enunciar los parlamentos, este elenco se ha ubicado estéticamente dentro de la dicción interpretativa, en términos de Pellettieri (2001). Ha convocado en sus funciones anuales a centenares de espectadores desde sus inicios. Su repertorio ha sido ecléctico abordando con frecuencia obras de Alejandro Casona o César Buero Vallejo, pero también llevando a escena algunas obras nacionales de autores como Carlos Gorostiza, Alberto Novión o Leopoldo Marechal. Entre los directores que han dirigido al grupo se encuentran: José Ricardo "Pepe" Arigossi (con más cincuenta y 
ocho temporadas dentro del grupo, y más de cuarenta ejerciendo la dirección), Alberto Iñiguez (también autor de varias obras estrenadas) y Nené Fernández. Y entre sus actrices y actores más recordados se encuentran: María Dolores Arigossi (la primera actriz, con cincuenta y cuatro temporadas dentro del grupo, esposa de Pepe Arigossi), Carlos Verón, Paulino Getzrow, Aline Godoy Prats, Alice Luque de Vera, entre otros/as.

Resulta interesante destacar que la provincia entera conoce de su existencia y permanencia, como también el estilo estético que ha elaborado durante tantos años. Así, se ha consolidado como una institución viviente que ha formado cantidad de actores, actrices, técnicos y directores en la región y hasta brindado funciones en colaboración o beneficencia de alguna causa social. Con marca propia, el Vocacional Corrientes ha logrado tener un público cautivo, mayoritariamente gente adulta, que lo ha seguido (y sigue) a través del tiempo y que, luego de las Veladas artísticas, ha convertido en costumbre el aguardar en el hall del Teatro Vera para ver y saludar a todo su elenco.

Por otro lado, el grupo Círculo de la Juventud Israelita comenzó con espontaneidad a representar algunas obras de autores reconocidos allá por 1950. Su primera etapa grupal se inició con La importancia de ser ladrón, de Enrique Gustavino y culminó con Ha llegado un inspector de John Boynton Priestley. Más tarde, por razones internas, el grupo se dividió y fue entonces cuando comenzó una segunda etapa grupal bajo la denominación Teatro Experimental Sholem Alejeim (T.E.S.A.). Su primera producción se trató de Todos eran mis hijos de Arthur Miller, estrenada el 11 de agosto de 1956, a la que le siguieron La zorra y las uvas de Guilherme Figueiredo (1957), Una ardiente noche de verano de Ted Willis, entre otras.

Contando con una sala teatral propia auspiciaron y albergaron obras de otros grupos como las del Vocacional Corrientes o las del Teatro Del Guarán (conformado posteriormente). Entre sus referentes se encuentran Paulino Getzrow, Rosa Widomliansky, David Lifschitz, Non Salis e Isidoro Levitzky (quien también fuera presidente de la Asociación y quien se encargó de la dirección del grupo por varias décadas). Para el T.E.S.A., el Vocacional Corrientes era su referente contemporáneo, en cuanto a estilo y dicción sobre la escena. Asimismo, tenían en cuenta las obras que se estaban dando en Buenos Aires y, al volver de viaje, traían noticias sobre lo que habían visto. Leían unas catorce obras y entre ellas seleccionaban las que tuvieran más personajes. Todos leían y opinaban sobre los textos y las correspondientes modificaciones a tener en cuenta. En su estética preponderó la representación de textos dramáticos realistas y el trabajo de mesa para discutir y opinar sobre la puesta a estrenarse. Conformado heterogéneamente por médicos/as, abogados/as, arquitectos/as lograron mantener la actividad durante treinta años con un público que los seguía producción tras producción. Realizando gran promoción de sus espectáculos, actuaban siempre a beneficio de la Asociación, además de haber realizado cuatro certámenes provinciales a los que concurrieron grupos de otras localidades, tales como Resistencia (Chaco), Goya, Mercedes, entre otros.

El legado de este grupo -cuyos directores/as fueron David Lifschitz, León Berezovsky, Isidoro Levitzky, Enrique Sheinkman, Frida Winik, Paulino Getzrow, María C. Getzrow, Nancy Sánchez, Enrique Feuerman, Alejandro Barboza y Gabriela Arce- ha sido la importancia de juntarse para hacer teatro como una excusa para compartir y conservar un espacio de sociabilidad. Y sus últimas producciones teatrales finalizaron en 1981.

Entonces, como primera fase del sistema teatral, los comienzos del teatro correntino demostraron ciertas discontinuidades e intermitencias debido a la falta de una sistematización adecuada que fuera incrementada por la ausencia de producciones locales. Luego, a partir de la conformación de estos grupos se manifestó una intención de 
cambio por conformar un incipiente sistema teatral, que se reflejó en el interés por llevar adelante producciones propias con mayor frecuencia de funciones. De esta manera, el teatro vocacional no profesional, sumado a la tendencia filo-dramática centralizada en una proyección y dicción escénica del texto dramático fueron las características estéticas desarrolladas predominantes de este primer período.

Al mismo tiempo, fue en los años sesenta cuando se produjo la aparición de otros numerosos elencos que desarrollaron una estética relativa a la adoptada por el teatro independiente de Buenos Aires, iniciada como Segunda Modernización del Teatro Argentino (Pellettieri, 2005). Tal fue el caso de Grupo 66 -desarrollado entre 1966 y 1970, cuyos directores a cargo fueron Paulino Getzrow, Rolando Díaz Cabral y Martha Rodríguez Aguirre, entre otros-, Grupo teatral Ansias, La voz del Tablado, Teatro Vocacional de Estudiantes de Odontología y AR-TE (Fernández, 2005) y el grupo CO.VO.AR. Este último, cuyo principal gestor, docente y director fue Juan Córdoba, inició su actividad en 1962 y perduró durante una década, abordando diversos textos dramáticos tales como La soga de Patrick Hamilton o Rashomon de Ryunosuke Akutagawa, que dieron lugar a una programación muy ecléctica.

Simultáneamente en esta década, y como lo anticipábamos en la contextualización cultural provincial, el carnaval en la ciudad capital comenzaba a mostrar novedosos matices. Decíamos que en 1961 se produjo una conversión organizativa que dio lugar a una concepción novedosa de la teatralidad, entendida como "puro arte en movimiento" (Fernández, 2007). La aparición de dos grandes comparsas dio origen a un nuevo tipo de carnaval. Atrás quedaban las carrozas y los autos de la clase alta que se paseaban por las calles, para dar lugar a las grandes comparsas que competían entre sí, creando coreografías propias. Como festividad tenía (y tiene, de algún modo) una capacidad ciertamente educativa, para transmitir circunstancias y condiciones histórico-estéticas a todo su público, el cual, inconscientemente, posee una especializada formación e instrucción en torno a la festividad. Así, desde la infancia, el pueblo entero aprehende el saber de este fenómeno estético y lo asimila como propio.

A fines de los años 60 la avenida costanera se poblada de más de mil comparseros y comparseras que danzaban al compás de tambores, mientras setenta y dos corsos se sumaban al festejo por los barrios. Este fenómeno, según Isaac "Taka" Benítez, lo marcó el inicio de las grandes comparsas que "sin tener formación ni en danza, ni en música, miles de personas formaban parte, como representación a cielo abierto. Esto en teatro jamás se ha visto acá" (Benítez, 2009). Así en la década del 70, Copacabana, bajo la dirección de José Ramírez, y Ara Berá, bajo la dirección de Dante Cena, se convirtieron en las dos grandes comparsas que permitieron pensar al carnaval como un verdadero hecho teatral de tinte popular aledaño a lo coreográfico, lo espectacular y lo participativo, momento en el que el carnaval correntino brillaba con todo esplendor.

\section{Segunda. Etapa teatral: 1970-fines de 1990}

La presencia de Dante fue un antes y un después. Empezó a aplicar técnicas sistemáticas. Hasta entonces, el teatro era social, societario, de pasatiempo. Y él, con el teatro Municipal, abre las compuertas de un nuevo teatro. Las de Barranco fue un hito para el teatro correntino. (Marcelo Daniel Fernández, entrevista personal, octubre de 2009)

En 1971, Dante Cena arribó la costa correntina -habiendo pasado por la vecina Resistencia, luego de dejar su Córdoba natal- y al conocer su carnaval quedó deslumbrado. Marcelo Daniel Fernández, por entonces fuera director de Cultura, le propuso quedarse en Corrientes para dictar talleres dentro del Programa Teatral en Barrios. 
"Buscábamos a través del teatro no despertar interés para que sean buenos artistas, sino buenas personas. La expresión teatral enseñaba expresarse mejor", recuerda Fernández. Cena aceptó y ambos llevaron adelante tal promoción cultural. Paralelamente, Cena comenzó a trabajar en la comparsa Ara Berá.

Como aquel programa tuvo un resultado muy positivo, se animaron a gestar otro desde la misma Dirección de Cultura y Turismo de la Municipalidad, dentro del distrito de la capital. Así surgió el Taller de Teatro Municipal. Allí, algunos de los/as chicos/as que habían participado de la experiencia previa en los barrios se acercaron a la nueva convocatoria. El taller funcionó durante siete años consecutivos y su repertorio comprendió mayoritariamente obras nacionales y correntinas. El régimen de clases diarias era de cuatro horas, logrando una tarea de entrenamiento, ensayos y mantenimiento muy productivos. Asimismo, los fines de semana eran destinados para realizar las funciones por los barrios, armando escenarios en las veredas y convocando a toda la vecindad. Incluso llegaron a trabajar en el Teatro Vera.

Cuando estrenaron ...Si no que vayan saliendo de Marily Morales Segovia, el taller se animó a trabajar una estética de realismo crítico, pero en 1974, con el estreno de Las de Barranco, de Gregorio de Laferrere en el Teatro Vera y llevada a los barrios también, logró una realización memorable que alcanzó una mayor impronta poética planteada desde lo escenográfico-visual. Cena le había propuesto a la diseñadora de espacio y vestuario una casa realizada con caños de luz cubierta por paredes de tules de mosquitero grueso, para que el salón, las habitaciones y hasta el balconcito de la casa familiar tuvieran paredes transparentes apoyadas sobre una estructura de metal que quedaba visible, lo que daba un marco metafórico desde lo espacial. La misma puesta fue pensada como itinerante para ser llevada a los barrios aledaños, teniendo a Betty Barboza interpretando a La Carmen, y a Carlos Salvado como parte del elenco. Así, la figura e impronta de Dante Cena direccionaron el nuevo rumbo del teatro correntino, según cuenta Marcelo Daniel Fernández. Como innovador y propulsor del teatro serio en Corrientes, se animó a abordar nuevos procedimientos en pos de una formación adecuada para la realización de un teatro comprometido con otras estéticas.

Durante ese mismo año, 1974, Cena también llevó adelante el Taller de teatro de la Escuela Secundaria de Comercio Manuel Belgrano, y entre los alumnos que asistieron estuvo Ángel Quintela, quien más tarde será otro referente hasta la actualidad. A fin de año, aquella cursada culminó con la puesta de Losfantoches de Carlos Solórzano. $\mathrm{Al}$ año siguiente, Quintela permaneció como ayudante de Cena y juntos prepararon el estreno de la comedia musical Luna y Yerutí de Marily Morales Segovia, realizada por todo un elenco de adolescentes, en la que se tematizaba la historia de animales de la zona, cuya musicalización estuvo a cargo de Romero Maciel.

En 1976, último año del taller escolar, estrenaron Coenbotá-amanecer, en guaraní-, con autoría de Segovia también, que contó con la participación de ciento treinta alumnos/ as -entre ellos/as cuarenta artistas en escena, además de músicos/as, orquesta, coro, iluminadores, escenógrafos, vestuaristas y publicidad- (S/A, 1977: 12) y con música folklórica, a cargo de la artista Teresa Parodi. Allí se narraba la aparición de una abuela muerta que reclamaba sus raíces y cuestionaba el hacer de cosas importadas de afuera, desatendiendo al hacer propio del lugar. Con esta propuesta definida como "alegato reivindicatorio de nuestra esencia" (S/A, 1977:12) cerraron una etapa de inserción juvenil en la que el objetivo llevado a escena fue rescatar y valorar la propia cultura pre-colombina.

En ese mismo año, 1976, el país sufrió otro golpe de Estado y se inició la última dictadura cívico-militar (1976-1983). Durante esos años fueron varias las restricciones efectuadas hacia la actividad teatral, entre ellas las condiciones de expresión habían 
sido delimitadas, prohibidas. La metáfora, para muchos/as artistas, resultó una herramienta invaluable que les permitió seguir expresándose aún en lamentables circunstancias socio-políticas. Algunos recuerdan el control militar en la entrada del Teatro Vera antes y después de cada función. Mientras que, en los archivos de ese teatro, los programas de mano registran una política cultural estructurada a partir de espectáculos con grandes figuras del Ballet ruso -entre ellas Maia Plisiétskaia, que visitó el país en 1978- y varias visitas de la Comedia Nacional de Buenos Aires, con obras como Matinata de Jorge D`Elía y una versión del Juan Moreira de Eduardo Gutiérrez.

En 1979 apareció publicado en un diario local un aviso que convocaba a correntinos/ as a formar parte de un curso de formación actoral, cuyos profesores a cargo serían: Carlos Swchaderer (en actuación), Dante Cena (para Expresión corporal) y Adela Ceni (como profesora de literatura y análisis de textos). La repercusión fue masiva y a fin de año se encontraban ensayando una versión de la obra de Gutiérrez, denominada $Y$ Juan Moreira fue. La estética adoptada combinaba teatro, danza, mimo, con momentos dramáticos. Se trató de simples exclamaciones que prácticamente eludían el uso de la palabra hablada. Finalmente, el 21 de junio de 1980 se produjo el estreno. Y a partir de este espectáculo se conformó el grupo teatral Del Guarán (que significa mezcla de guaraní y español, a la par que se designa un árbol -Lapacho Guarán amarillo-), cuyos fundadores/as fueron Ángel Quintela, María Esther Aguirre, Alicia Fernández y Raúl Sorabela, entre otros/as integrantes iniciales. En aquel tiempo, el teatro de acción de Pina Bausch visitaba Buenos Aires, cuya la mixtura entre danza-teatro era algo que resultó inquietante y motivadora para el grupo. Algo similar a la fusión carnaval-teatro, la estética lograda por entonces dio lugar a una puesta con mucha danza en la que el público -acostumbrado a esa fusión desde el carnaval- respondió con gran aceptación y acercamiento. Luego del estreno, realizaron giras por el interior de la provincia completando la experiencia educativa y formativa. Y si bien la versión fue aceptada ampliamente, el grupo no volvió a retomar esa estética desarrollada.

Las segundas producciones teatrales Del Guarán fueron Los de la mesa diez de Osvaldo Dragún, dirigida por Ángel Quintela y El debut de la piba, de Roberto Cayol, dirigida por Cena. Ambas producciones fueron estrenadas en 1981, y cuyos elencos ensayaron paralelamente, ya que se trataba del mismo grupo teatral. Con estas puestas aparece un nuevo lenguaje en el objeto producido. El grupo desarrolló una veta de farsa-comedia con un encuadre realista de la que no se desprendería en puestas posteriores. En 1982, se produjo otro hito dentro de la historia del teatro en la capital, y especialmente para el propio grupo Del Guarán: el estreno Ánimas de día claro de Alejandro Sieveking.

En 1983, Cena dejó el grupo y Ángel Quintela fue quien asumió la dirección. Del Guarán siguió produciendo obras de teatro por varias décadas, las cuales han estado a cargo del propio Quintela y de María Esther Aguirre. Por otra parte, si bien han abordado diferentes repertorios según las épocas -textos regionales, comedias, dramas y obras absurdas- se puede considerar que en sus puestas ha preponderado un realismo moderado. Dentro del panorama teatral actual, el grupo de teatro Del Guarán se ha convertido en uno de los grupos que continuó con actividad constante, no sólo por las puestas llevadas a cabo, sino también por los talleres de formación actoral que dictara Quintela. Además, es uno de los pocos grupos de la capital que cuenta con una sala propia, como veremos más adelante, en donde promueve una constante actividad cultural.

Ahora bien, a mediados de los 70 y principios de los 80, otros grupos surgieron a la par en la ciudad capital; ellos fueron el Grupo NOAR -desprendido del T.E.S.A. (cuya actividad se extendió entre 1979 y1985)-y el Centro Cultural Correntino que -fundado en 1979 y en continua actividad- dirigido por Yani Zimerman, caracterizándose por abocarse espectáculos compuestos por elencos de niños/as y adolescentes. 
El retorno democrático de diciembre de 1983 trajo consigo la posibilidad de cambiar el rumbo del panorama artístico, propiciando un auge cultural en el que las manifestaciones artísticas se potenciaron en diversas áreas. Los grupos teatrales que lograron permanecer luego de la dictadura, como el Vocacional Corrientes o el T.E.S.A., continuaron a la par de Del Guarán, que se asentaba y consolidaba en la ciudad capital. Fue en ese entonces que surgió el Taller de Teatro de la Escuela Regional, el cual marcó un antecedente en lo que refiere a la incorporación de teatro en las escuelas. En 1984, la Escuela Normal José Manuel de Estrada, más conocida como la regional, desarrolló en sus aulas una actividad teatral ligada al objetivo de dinamizar la enseñanza. Adriana Covalova, rectora de la institución desde 2002 e impulsora en el Área de Historia, se encargó de abordar temas de su materia como la Guerra contra el Paraguay a partir de recursos teatrales. Pronto la experiencia se propagó en la institución hacia otros/as docentes. Así se inició un taller de teatro educativo para aquellos/as alumnos/as que quisieran quedarse en horario extra-escolar. La propuesta, ampliada al área de Ciencias Sociales consistía en tomar un tema e investigarlo. Los/as alumnos/as iban a la biblioteca y aportaban datos para que, en conjunto, se pudiese armar una obra teatral.

En 1987, el escritor Florencio Godoy Cruz, profesor de Literatura, promovió la realización de una obra de teatro junto a otros profesores con motivo del festejo del centenario de la escuela. Esto dio lugar a otro taller dentro de la institución, el Taller de teatro de docentes, al que, posteriormente, convocaron a Dante Cena como director. La primera actividad consistió en incorporar técnicas de actuación y de expresión corporal. Así, poco a poco, se creó una revolución dentro de la escuela que no tardó en hacer aparecer las quejas de otros/as profesores/as. Sin embargo, la rectora los apoyó y el emprendimiento continuó. A fin de ese año estrenaron Para el pueblo yo soy Pancho, de Aldo Grasso en el salón de actos, y más tarde la repitieron en el Teatro Vera y en otras escuelas secundarias.

En 1988, los talleres extra curriculares continuaron con más formación y se los denominó Talleres de teatro en Ciencias Sociales destinado a alumnos/as, reforzando la experiencia iniciada desde 1985. Etapa de investigación, técnicas de actuación aprendidas con Dante y, finalmente, la creación colectiva de una obra. A partir de ello estrenaron La forestal, sobre la cual, una vez finalizada la función, abrían un debate relativo a la temática tratada. Iniciativa que combinó enseñanza de teatro con temas de historia. En estos talleres se formaron Karen De Micheli y Alejandro Barboza, entre otros/as actuales actores/directores referentes de Corrientes. Posteriormente, se incorporó la enseñanza de teatro para toda la escuela, ampliando la metodología empleada hacia otras áreas. Este método funcionó hasta 1997 y, a partir de la Ley Federal de Educación, la metodología se modificó y derivó en talleres curriculares para cursos inferiores.

Asimismo, durante estos primeros años de advenimiento democrático también surgieron otros grupos teatrales, entre ellos se pueden mencionar: el grupo Aty Mangoré (1983-1984); Los Caminantes (1984); el Teatro Nuestro Tiempo (1983-1984); el Constantín Teatro Club (1985) y la Agrupación Corrientes (1985).

Paralelamente, en 1987, se fundó La Barraca, grupo que impactó por su estudio y dedicación en cada producción emprendida. Entre sus directores/as estuvieron Jorge Portela, Paulino Getzrow, Nené Fernández y Alice Vera de Luque. Representando autores nacionales y extranjeros, La Barraca logró realizar largas temporadas con un público que los seguía asiduamente. Mientras que, en ese mismo año, Ricardo Thierry Calderón de la Barca y Raúl Sorabela fundaron el grupo de teatro independiente El Aleph. Así, estos dos grupos, La Barraca y El Aleph, junto a Del Guarán -que en 1986 lograba pleno éxito en una temporada que superó las treinta funciones de Los Indios estaban cabreros- fueron los encargados de formar los nuevos actores y actrices de la región. 
Por su parte, El Aleph inicialmente abordó autores clásicos o nacionales y, posteriormente, se volcó hacia obras de la propia autoría de Thierry. En esta dirección perfiló una estética paródica, con técnicas de music-hall. En un momento en el que la reapropiación del espacio público cobraba otro vigor, realizaron Muchas felicidades por plazas y oficinas públicas, bajo la dirección de Thierry, mientras Raúl Sorabela personificaba a la señora. Toda la acción transcurría en una casa, dentro un ambiente familiar. Sin embargo, Sorabela luego fue muy reconocido por otro personaje femenino interpretado $\tilde{N} a$ Conché (Doña Conché), en un unipersonal realizado entre 1988 y 1995, que ha dejado un recuerdo entrañable en el público local.

Por otra parte, dentro de la multiplicidad de expresiones artísticas despertadas a partir del advenimiento democrático -y que se prolongaron en la década siguiente- se llevó adelante el programa cultural Danza Libre. Este fue un encuentro nacional que duró aproximadamente diez años en el que artistas como Eduardo Sívori, Dante Cena y Julio López fueron algunos de los integrantes, gestores y participantes del proyecto. A su realización concurrieron varios grupos nacionales, entre ellos la Compañía Cisne negro, Duggan-danza, Núcleo danza, Brenda Angiel y su teatro aéreo, El descueve. El ciclo, que duraba aproximadamente diez días, tuvo un inicio algo acotado en la región, pero logró expandirse hasta obtener resultados a nivel nacional, convirtiéndose así en el único encuentro de danza del país, junto con el Teatro Nacional Cervantes de Buenos Aires que también dedicaba dentro de su programación un lugar relevante para los espectáculos de danza, tal como fue el ciclo Los martes de danza.

En definitiva, a partir de 1984, se produce una gran participación por parte de varias aristas artísticas. Y respecto del ámbito teatral, vale destacar la aparición de un teatro socialmente comprometido. En este sentido, el grupo Del Guarán y el grupo El Aleph se destacaron y lograron sedimentarse como los dos grandes semilleros de teatristas (varios de ellos actualmente en actividad).

La década de los 90 trajo otros aspectos relevantes como la conformación de nuevos grupos que generaron un incremento de la actividad en la capital provincial. En 1992, apareció el grupo La trastienda, cuyo objetivo inicial fue poner en escena textos capaces de provocar una identificación con el público. Así lograron permanecer durante diez años desarrollando un repertorio que, además de emoción, posibilitara alguna reflexión. Por su parte, Dante Cena estuvo a cargo de su dirección durante algunos años. La metodología adoptada comprendía un trabajo de investigación sobre el contexto social de las obras, previo a arribar el texto propiamente dicho. Tal fue el caso de Señoritas en concierto de Cristina Escofet, adaptada por el propio Cena, cuyo estreno fue en 1999. Con una estética de varieté y café concert, llegaron a más de treinta y cinco funciones durante tres años consecutivos. La adaptación consistió en incorporarle una parte dramática denominada las históricas en la que se abría otro cuadro con pequeños monólogos de Alfonsina Storni, Alicia Moreau de Justo, Camila O'Gorman, Lola Mora y Eva Perón. El elenco estuvo conformado por Adriana Covalova, Elvira Estrada, Alicia Fernández, Vicky Mecca y Karen De Micheli. Más tarde, en 2002, La trastienda estrenó dos obras: Historia tendenciosa de la clase media de Ricardo Monti y Almas con flecha de Gladys Gómez (su última producción). La trastienda fue otro de los grupos que gestionó tener una un espacio propio y, al momento del trabajo de campo de esta investigación, era inminente la inauguración de su sala Teatro de la ciudad, sobre la que volveremos luego.

Por otro lado, apareció el Grupo de Nancy Ojeda -a cargo de la actriz con una larga trayectoria teatral (1995) - y el grupo Ambaí dirigido por José María Gómez Samela. Éste último fue creado en 1999 con actores provenientes de grupos ya existentes, tales como Gabriela Arce, el propio Gómez Samela, Claudio López, Diego Paredes Ortigoza y Lucrecia Toranzos. Su fundación se produjo con el estreno de El nuevo 
mundo de Carlos Somigliana el 25 de mayo de aquel año y, a más de una década, continúa en permanente actividad. Uno de los propósitos del grupo era pensar al teatro en términos colaborativos. Desde sus inicios, sus integrantes confluyeron en una búsqueda por una dramaturgia del actor/actriz y, en esos años, Gustavo Benítez también formó parte de la agrupación. Luego, y continuando una influencia latinoamericana, realizaron obras con diferentes temáticas sociales hasta aproximarse a una idea de teatro colaborativo, donde la interdisciplinaridad se volvió punto de partida para nutrir sus propias producciones. Experiencia que, tal como recuperan algunos medios locales como la Revista Macedonia, se lo ha considerado como un grupo de teatro que une.

Asimismo, en los 90, Yhin Romero se desprendió del Centro Cultural Correntino (a cargo de Yani Zimerman) para crear su propio grupo dirigido, mayoritariamente, al público infantil. Habiendo desarrollado un teatro con cierta función social con obras con temáticas relativas a la prevención y salud en los adolescentes, sus espectáculos fueron llevados a diversas instituciones, escuelas o ligas y en algunas oportunidades también ha competido en las fiestas del INT. Por otro lado, otras de sus producciones musicales también han sido estrenadas en el Teatro Vera. Este es el caso de los infantiles ambientados con una estética del universo animado de Disney que, desde hace años, viene trabajando con éxito de taquilla.

Por su parte, Silvia Rivero -proveniente de una familia de teatristas, entre ellos, su tío fue el actor, director y dramaturgo correntino Alberto Iñíguez- también fundó su propio grupo en esta década. La iniciativa surgió como un emprendimiento propio a partir de querer incorporar al teatro como recurso didáctico en sus clases de inglés. Al mismo tiempo, el Vocacional Corrientes la convocaba a participar en una de sus puestas anuales. Así, poco a poco, Rivero fue vinculándose cada vez más con la actividad, hasta decidir dictar autónomamente un taller para chicos y chicas. Finalmente, en 1998, surgió Bambalinas. Sin embargo, debido a la escasa relación que mantenía con otros talleres de teatro locales, comenzó una búsqueda personal por encontrar nuevos materiales y técnicas de actuación sobre las cuales enseñar. Así fue que dio con la técnica de impro (improvisación) sobre la cual había bastante material en inglés. Entonces, se perfeccionó en esa dirección tomando cursos en Buenos Aires con maestros especializados en esa técnica. Se ha convertido en una referente de la impro dentro de la provincia y por su grupo ya han pasado dos generaciones de actores niños/as y adolescentes.

En síntesis, en esta segunda etapa que comprende temporalmente tres décadas y diferentes momentos socio- políticos atravesados, el sistema teatral correntino consiguió, mayoritariamente en la capital, una canonización de la actividad ligada a un compromiso social y vocacional. El riesgo por buscar nuevas técnicas y estéticas incrementó el interés por una profundización más adecuada en la formación de actores/actrices y directores/as. Entonces, mientras que el auge cultural democrático fortaleció a los grupos existentes, también permitió un florecimiento de grupos emergentes. De esta manera, cuando concluye la década del 90, el panorama cultural reflejaba un sistema conformado sólidamente, apto para contener la multiplicidad de propuestas estéticas desarrolladas.

\section{Tercera etapa teatral: fines de 1990- 2010 el fomento institucional y la formación teatral}

Esta tercera etapa se inicia a partir de 1998 cuando el panorama teatral del país cambió fructíferamente gracias a la creación del Instituto Nacional del Teatro. Con esta entidad, sin duda, se abrió un ciclo de mayor federalización e intercambio artístico. 
Aun cuando su gestación y momentos preliminares resultaran algo complejos, debido a la organización correspondiente para llevar adelante tamaña labor, poco a poco fue asentándose hasta ocupar, hoy, un lugar central como organismo estatal capaz de apoyar y promover la actividad teatral a nivel nacional. El primer representante que tuvo Corrientes a nivel regional fue Ángel Quintela quien, terminado su período en 2006, fue sucedido por Mauro Santamaría (dramaturgo, escultor y director teatral). A partir de su conformación, la actividad en la región se vio altamente motivada por el otorgamiento de diversos subsidios para la producción de obras, mantenimiento de salas, capacitación y perfeccionamiento con docentes de otros puntos geográficos del país, entre otros apoyos económicos cedidos. Con los primeros Planes de Fomento se gestaron varios grupos en Ituzaingó; en San Roque; en Esquina -el grupo Ya Ye Junta que en alguna oportunidad fue dirigido por Thierry-; en Bellavista -el grupo Génesis, dirigido por Gabriel Massoleni, que presentó Homofobia y Sed padecerás, y que continúa en actividad-; y también en la Capital el grupo Coarte, dirigido por Gastón Alexis.

Luego de una década de existencia, el INT continuó otorgando subsidios a producciones de elencos ya conformados o para aquellos que se reunieran en para realizar un espectáculo concertado. Al mismo tiempo, continuó colaborando en el otorgamiento de becas de perfeccionamiento para directores/as, dramaturgos/as, actores y actrices y se ha encargado de la organización de las fiestas provinciales, regionales y la nacional. En estas fiestas tuvieron (y tienen) lugar mesas redondas con participación de directores/ as, técnicos/as de escena, actores y actrices, escenógrafos/as y miembros directivos del organismo, las cuales colaboran en fomentar el intercambio de opiniones, experiencias y diálogo entre teatristas de diferentes generaciones, localidades y realidades diversas.

Ahora bien, respecto de la comunicación e intercambio que fueron consolidando la actividad a nivel institucional, se encuentra otro momento importante para la formación profesional: la creación de la carrera de Profesor en Teatro (Instituto de Formación Docente en la Escuela Normal de la ciudad capital), iniciada en 2006, un año después de haberse iniciado en la capital vecina de Resistencia (Chaco). Si bien esta carrera responde a la necesidad de una formación teórica académica, no estuvo dirigida hacia la formación específica de actores y actrices, sino que -como su nombre lo indica- se trata de un profesorado oficial. De todas formas, ha marcado un avance dentro de la región al considerar al teatro como carrera pedagógica y materia dentro de la currícula escolar. Esto también señala una legitimación de la profesión por tratarse de una enseñanza de nivel superior terciario. Asimismo, su existencia posibilitó no sólo el fomento de diversas lecturas y materiales teóricos, sino también nucleó el acceso correspondiente a los mismos por parte de un público interesado. En definitiva, su creación ha generado un nuevo espacio físico y social para el teatro y para la sociedad correntina en general, formando profesionales con una clara salida laboral.

La década del 2000 comprende, entonces, un apoyo constante del INT y la posibilidad de formación de profesores/as de teatro. Se observa que junto con ello aparecen nuevos grupos y nuevas tendencias escénicas de la mano de jóvenes artistas. Tal es el caso del Grupo Germinal, que nace en enero de 2005, bajo la dirección de Lorena Busciglio y Facundo Giorda, quienes consideran que, motivados por la ausencia de grupos oficiales actuales que representaran a la provincia, se propusieron llevar adelante algo nuevo por experimentar en materia teatral. Así emprendieron la búsqueda de una formación más integral que abarcara también lo teórico, aun sabiendo de la existencia del profesorado, pero marcando otro camino que profundizara lo artístico actoral, dramatúrgico y directorial, armando su propia estructura. Sentían no tener un referente que les indicara cómo generar un producto y venderlo. Entonces, comenzaron dictando simples talleres para adolescentes. La tarea de acercar el teatro a la gente, tal como indica su directora, se convirtió en "Una evangelización persona por 
persona" (entrevista personal realizada a Lorena Busciglio por la autora, Corrientes, octubre de 2009) no sólo a la hora de convocar público para sus producciones sino también al convocar alumnos/as para sus talleres de actuación.

Con la primera fiesta provincial en la que participaron conocieron teatristas que podían vivir de la actividad. Así, averiguaron cómo crear una autogestión, algo que los caracterizó, luego, como grupo. Lograron obtener subsidios del INT y emprendieron pequeños espectáculos itinerantes capaces de ser trasladados colegio tras colegio, generando un circuito sustentable para la profesión, capaz de hacerles vivir del teatro. Los integrantes de Germinal manifestaron, luego de llevar unos años en la actividad, haber creado una estructura propia basada en la impronta del trabajo y el entrenamiento. Así rescatan el haberse arriesgado por intentar llevar adelante esa pasión autogestiva, que fuera contagiada a los/as diferentes integrantes que el grupo ha sabido reunir, pero fundamentalmente apoyada por el INT. Como grupo conformado por jóvenes teatristas que manifiestan asiduamente su ímpetu por trabajar y vivir de la actividad, Germinal se han vuelto uno de referentes actuales de las nuevas tendencias que demuestran un camino hacia otros lenguajes, en donde la puesta en escena es una búsqueda constante por explorar.

Otro referente de la actualidad teatral correntina reciente es el actor, docente y director teatral Alejandro Barboza quien dirige desde 2006 al grupo Chico Pleito -fundado por el propio Barboza, Silvina Bordón, Víctor Cardozo y Milton Rosés-. Barboza desde un año antes venía dictando junto a Víctor Cardozo talleres de teatro en la sala El asunto y, luego de su cierre, se trasladaron al café El Mariscal. Estudiante del Profesorado en Teatro de Resistencia, ha dirigido varias obras, entre ellas Tartufo, de Molière, estrenada en 2007 y representada a lo largo de varios años. Pensada para ser itinerante esta puesta ha sido conformada por un elenco numeroso del taller de formación teatral y del grupo de teatro "Chico Pleito" -Paula Manghera, Víctor Cardozo, Gastón Alexis, Selena Larrosa, Nancy García, Silvia Bordón, Milton Rosés, Mariel Moretti, entre otros/as-, y su estética combinó la adaptación de la comedia con una inspiración visual en las obras plásticas del artista Molina Campos. Con ella inauguraron el "Teatro Sáenz Peña" del Chaco, lo que resultó todo un acontecimiento para el grupo, puesto que manifestó un reconocimiento del mismo dentro del campo teatral.

Entre 2008 y 2009, trataron de unificar proyectos y objetivos en los talleres que dictaban. Se preocuparon entonces por profundizar la parte teórico-práctica de sus clases, algo de que ellos tuvieron como carencia en los inicios de su propia formación. Autores como Eugenio Barba o Cipriano Argüello han sido la base teórica sobre la cual investigaron la dramaturgia del actor/actriz. Además, según Barboza y Cardozo, su trabajo de formación ha consistido en explorar el trabajo corporal y la comprensión del relato actoral como objeto expresivo en cada estudiante en pos de formar actores y actrices con herramientas propias para que sus cuerpos logren una presencia escénica, apuntando a construir una actuación ligada a la calidad corporal activa y a la eficacia del entrenamiento.

De esta manera, esta tercera etapa que ubicamos en el teatro correntino podemos decir que estuvo signada por un mayor diálogo e intercambio entre artistas debido, entre otras causas, a la creación del INT y a la preocupación por consolidar la formación teatral. Nuevas generaciones arriesgaron la búsqueda de lenguajes escénicos más eclécticos-generando recursos o refuncionalizando otros del pasado-intensificando, al mismo tiempo, la posibilidad de convocar y formar nuevos públicos.

Por su parte, el INT y las fiestas provinciales crearon las condiciones propicias para generar un panorama que, sin acotarse a una localidad específica, posibilitó una red de comunicación entre los diferentes lugares de la región. Mediante el diálogo entre realidades disímiles, pero cercanas, y la observación de otras 
producciones se habilitó una concepción más amplia de lo que se entendía por teatro correntino, encausada entre los propios integrantes y en relación con el afuera extra-provincial. Este aspecto conceptual, además, posibilitó en los últimos tiempos, problematizar una formación más integral ligada a una necesidad por definir qué tipo de teatro puede resultar más autóctono (o no) y definir cuál sería ese tipo/estilo estético propio, a partir de qué técnicas y qué particularidades. De esta manera, la actualidad reciente presenta un panorama heterogéneo de estéticas y de formación, en el que cohabitan los grupos más definidos -en actividad permanente desde hace décadas- con aquellos más recientes que, incesantemente, buscan la autodefinición.

\section{Los espacios teatrales y el público en la ciudad Capital}

Ahora bien, como anticipamos, para cerrar esta primera parte del trabajo de investigación nos detendremos en un aspecto puntual del teatro correntino que también varió según los diferentes períodos hasta aquí analizados, nos referimos a los espacios teatrales de la ciudad capital. Evidentemente, dentro del campo teatral correntino la recepción es un aspecto que ha presentado ciertas particularidades y, en el momento del trabajo de campo, se podían establecer dos circuitos, el oficial y el independiente, los cuales se definían, entre otros rasgos, por los espacios teatrales competentes a cada uno, respectivamente.

Al observar el circuito oficial, el espacio emblemático con el que nos encontramos en primer lugar es el Teatro Juan de Vera, sala de mayor relevancia, reconocimiento y legitimidad dentro de la región que, aun cuando no resulte ser visitado recurrentemente por la mayoría de la población, todos/as saben de su existencia y resaltan su belleza arquitectónica -una edificación muy pintoresca de estilo Belle Epoque (1900)que impacta dentro del casco histórico. Su historia se remonta a fines del siglo XIX y principios del siglo XX, cuando su construcción posibilitó un ámbito propicio para desarrollar un teatro vinculado con lo lírico- dramático, acompañado por una concepción de lo teatral ligada al encuentro social de las clases más aristocráticas. Su estructura cuenta con tres niveles, columnas, hall y escalinatas de mármol, platea rodeada por palcos bajos y tertulias, más palcos altos, cazuela y paraíso en las plateas altas, además de contar con una cúpula corrediza que permite ver el cielo y disfrutar del aire que por allí entra en las noches de verano.

Asimismo, su cielo raso posee una cúpula cóncava, cuyo mural decorativo ha sido restaurado en sucesivas oportunidades. La realizada en 2005, a cargo de José Ramírez, compuso una imagen temática que ilustra desde la mitología guaraní hasta acontecimientos relevantes dentro de la historia cultural y teatral de la provincia, incluyendo grandes obras de diversos géneros teatrales representadas en el teatro, momentos pre-colombinos, raíces musicales, entre otros elementos alegóricos. Habiendo sido inaugurado el 9 de julio de 1861 con la ópera Aída de Giuseppe Verdi, y reinaugurado en 1913, rápidamente se convirtió en la sede preferida de más de una Compañía española o porteña -tales como la de María Guerrero y Fernando de Mendoza, Pablo Podestá, Orfilia Rico, Enrique de Rosas, Angelina Pagano, o la de José Ramírez, entre otras-, las cuales venían de Buenos Aires y ofrecían sus espectáculos, para luego seguir camino hacia el Paraguay. Su extensa trayectoria ha reunido una programación de espectáculos eminentemente líricos, como también algunos de danza o ballet.

En la década del 50 se presentaron sucesivas veladas artísticas en las que se combinaban un popurrí de representaciones a cargo del legendario grupo de teatro Vocacional Corrientes. Asimismo, en esa década lo visitaron grandes compañías porteñas tales 
como la de Mecha Ortiz-con La esposa constante de Somerset Maugham, entre otras-, la Compañía Argentina de Comedia -con La mujerzuela respetuosa de Jean Paul Sartre, con las actuaciones de Silvia Nolasco y Claudio Martino-, la de Pepita Muñoz y Benito Cibrián -con Su primera mentira de José María Yorik- entre otras, además de espectáculos de revista-como los de Amelita Vargas, Alfredo Barbieri y Pedrito Quartucci- o musicales -como el de Los Fronterizos-. También se presentaron Los Niños cantores de Viena, grandes figuras del Teatro Colón de Buenos Aires, los Títeres de Podreca y algunas compañías de Radioteatro, como la Gran Compañía Radioteatral dirigida por Carlos Norberto Aguilar.

A fines de los 50 y principios de los 60, el Teatro Vera funcionó como sala de cine -entre los films proyectados se pueden mencionar La verdad no tiene fronteras (1956) de Alexander Ford, Otelo (1955) de Sergei Yutkevich, El rey y yo (1956) de Walter Lang, entre otros- y también sirvió de sede para varios grupos locales como el Vocacional Corrientes, el T.E.S.A., CO.VO.AR. y el Grupo 66.

Más tarde, a fines de la década de 1970, bailarines de otras partes del mundo -tales como los del ballet del Cáucaso, de Tahití, de Cuba, de Venezuela, de Montecarlo, los mundialmente reconocidos Ballet Russes o la principal bailarina del Bolshoi, Maia Plisiétskaia- fueron los protagonistas de las temporadas programadas, las cuales también estuvieron combinadas con otros espectáculos de teatro, música, infantiles. Todo esto tuvo lugar a partir de 1977, bajo la dirección general de José Ramírez -arquitecto, escenógrafo del teatro desde 1972 que también había dirigido la comparsa Copacabana- quien ocupó ese rol durante veinte años. Ramírez recuerda que tuvo que atravesar distintos gobiernos y épocas muy disímiles en todo ese período. De grandes presupuestos para la importación de compañías de ballet en los 70, hasta notables reducciones que hicieron que la programación y calidad de los espectáculos se viera altamente modificada. Con el advenimiento democrático, Ramírez recuerda el ciclo Danza Libre, mantenido durante toda la década. Sin embargo, en los 90, se produjo una nueva reorientación de la programación del teatro hacia espectáculos de entretenimiento, más cercanos a lo comercial (en el caso de espectáculos provenientes de Buenos Aires) y también se destinó un alto índice de la grilla horaria a ensayos y espectáculos provenientes de escuelas privadas de nivel medio. De esta manera, se podría decir que, si bien la arquitectura admitía en sus inicios una preferencia por lo lírico dramático, con el tiempo, el Vera admitió diferentes tipos de espectáculos. Así, continúa siendo la sala oficial de mayor importancia dentro de la provincia, por lo que estrenar en el Vera encierra en el imaginario social, de algún modo, un cierto prestigio de legitimación. Vale aclarar que casi todos los grupos locales (hayan sido de tipo independientes, vocacionales) han estrenado sus obras en este teatro. Pero ocurre que, debido a la gran cantidad de localidades que presenta, y frente a un caudal de público que se agota rápidamente, el teatro no les ha resultado plausible como espacio para mantener una temporada muy extensa, sino que, por el contrario, luego de haber estrenado, muchos de los grupos han migrado hacia otras salas más pequeñas para continuar con sus respectivas temporadas en cartel.

En relación con el público asistente, podemos decir que, por un lado, el Vera convoca cierto público cautivo que considera al acto de ir al teatro como un hecho social, es decir, a un ámbito de sociabilidad con cierta prestancia. Y, al mismo tiempo, se observa una preferencia por un teatro de tinte comercial -importado en espectáculos realizados por grupos de Buenos Aires o extranjeros que se encuentran de gira- o por espectáculos de grupos locales más tradicionales.

Por otro lado, habría un público minoritario en la ciudad que gusta de otro tipo de espectáculos, con otras búsquedas poéticas y estéticas. Estos espectadores/as se 
ubican, mayoritariamente, en el circuito independiente y que, sin ser cautivo de un lugar, como ocurre con el Vera, se reconfigura según cada propuesta escénica ofrecida. Por lo que, en esta otra arista de la actividad, el esfuerzo por instaurar las producciones propias como parte de un panorama teatral profesional presenta otras y mayores dificultades para lograr la asistencia del público local.

Paradójicamente, como hemos mencionado, contar con un teatro oficial con capacidad para albergar a más de seiscientos cincuenta espectadores/as, resulta para los/as teatristas locales la imposibilidad de mantener un espectáculo a largo plazo. Quienes allí estrenan, lo hacen mediante una única función. Esta característica no es menor a la hora de analizar las temporadas en cartel, la oferta teatral y el devenir de la actividad propiamente dicha, por lo que durante mucho tiempo fue una preocupación poder contar con otras salas más pequeñas, ligadas al circuito independiente. Claro que esta inquietud también implicaba otros interrogantes ¿cómo lograr que esos otros ámbitos periféricos lograran aparecer? y una vez abiertos ¿cómo lograr su mantenimiento? Y ¿cómo conseguir público? Muchos/as teatristas coinciden en que ha sido y es necesario crear la necesidad de ver teatro, al considerar que la gente de la región no está acostumbrada a asistir a una sala teatral por motus propio, excepto que se trate de figuras conocidas o televisivas (las cuales sólo se presentan en el Vera). Por lo que poder pensar en realizar una temporada continuada en el tiempo, les resulta algo casi imposible incluso en los espacios más pequeños finalmente conseguidos.

Durante las entrevistas, varios/as teatristas independientes han coincidido en que el salir de gira por el interior y por los barrios de la provincia resulta una experiencia sumamente gratificante y concurrida. Sin embargo, también advierten, que se trata de un público que más allá de gustar por lo teatral, luego de ocurrida la función no se acercan hasta la capital para asistir a otro espectáculo. Y coinciden en que faltaría una formación de públicos, más allá de las propuestas que el teatro oficial pueda ofrecer.

Ahora bien, dentro de esos otros espacios que fueron construyéndose con el paso del tiempo para suplir la carencia edilicia, encontramos varias salas del circuito independiente. Fue en 1988 cuando el grupo Del Guarán vio la posibilidad de llevar adelante la gestión de una sala propia y en 1989 lograron inaugurar la Sala Mariño, en el salón de actos de la biblioteca homónima -cuyo edificio había sido inaugurado en 1910-. En un espacio rectangular con capacidad para albergar a sesenta personas, con escenario frontal de caja negra, se convirtió prontamente en la sede primordial de otros grupos independientes, volviéndose un polo central para las producciones teatrales de ese momento. Desde entonces funciona presentado obras propias Del Guarán y de otros elencos. Además, allí se realizó el Primer Festival de Teatro de las Siete Puntas, a partir de un convenio de reciprocidad entre el grupo Del Guarán, la Sala de la biblioteca y Linfocitos teatro, cuya coordinación general estuvo a cargo de María Esther Aguirre. El encuentro, declarado de interés cultural por la subsecretaría de Cultura de la Provincia de Corrientes, se pensó para seguir fomentando el intercambio de la actividad y el diálogo entre teatristas. En su primera edición se presentaron el grupo Mesopotamik (Corrientes), Linfocitos (Corrientes), Chico Pleito (Corrientes), Compañía Escénica (Paso de los Libres), Candilejas (Goya), Ambaí (Corrientes), Tonio López (Chile), Actores Unidos (Chaco), junto a otras actividades ligadas a la dramaturgia y al entrenamiento actoral.

Por otro lado, y a partir de la necesidad de generar otros espacios alternativos destinados a ensayar, a dictar seminarios o a presentar obras del circuito independiente, apareció la sala del café literario El Mariscal, ubicada en su primer piso. Este espacio cultural pertenece a un edificio histórico de la capital, en la que antiguamente había funcionado un almacén de ramos generales de la familia Nalda y hasta fue destinado como dependencia de una obra social. Sin embargo, Gabriel Romero lo reabrió junto a otro socio y poco a poco le fue dando un carácter de espacio cultural, como café 
literario y café concert. Por allí pasaron grandes personajes y ha servido de sede para exposiciones, eventos culturales, conferencias, espectáculos teatrales, muestras de artes plásticas y fotografía, espacio de biblioteca y archivo, entre otras actividades. "La mesa de los dinosaurios" fue un grupo de intelectuales que se reunía semanalmente en una de sus mesas. De esta manera, el café se ha convertido en una sala reconocida por su historia arquitectónica y por la actividad interdisciplinaria programada constantemente.

Otra sala que surgió durante los 90 fue El asunto, cuya iniciativa estuvo a cargo de Jorge Frete y Karen De Micheli. Nacida como un micro-emprendimiento de esta pareja de teatristas, esta sala tuvo el objetivo primordial de funcionar como un espacio donde ensayar y poder brindar pequeñas obras, principalmente dedicada al teatro de títeres. Ellos recuerdan que gracias a un subsidio del INT lograron poner sillas en la platea y poco a poco crearon un ámbito pequeño pero acogedor. Sin embargo, resultó difícil sostenerlo en el tiempo, por lo que debieron cerrar sus puertas en 2008. Consecuentemente, el Museo de Artesanías Folclóricas se habilitó como espacio teatral posible, y su patio colonial empezó a ser utilizado como espacio escénico. Mientras que, un barco estacionado (embarcado) en la costanera, tomó forma de espacio teatral dando lugar al llamado El flotante. Este último, además de poseer un taller de papel reciclado a cargo del responsable del lugar Roberto Villalba, también comenzó a funcionar como sala de exposiciones de artes plásticas (esculturas de Mauro Santamaría, entre otros/as artistas). Allí, el grupo Germinal estrenó varias de sus obras, intentando mantener temporadas durante varios los fines de semana. Ubicado en un lugar privilegiado resulta de gran atractivo no sólo para los/as habitantes de la ciudad sino también para los/as turistas.

Las otras salas que permanecieron con el tiempo, han sido la de la Sociedad Sholem Alejeim y la de la Sociedad italiana (ubicada a la vuelta del teatro Vera) que cuenta con dos salas propias. Asimismo, luego de tres años de trabajo intenso, en noviembre de 2009, se produjo la inauguración tan esperada de una nueva sala: el Teatro de la Ciudad. Este emprendimiento fue realizado por la Municipalidad de la ciudad, que contaba con el predio, en colaboración del grupo teatral La Trastienda -integrado por Antonia "Tony" Monzón, Vicky Mecca, entre otras actrices gestoras- conformado como ONG y contó con el apoyo del INT. La idea de esta sala surgió para articular la actividad teatral desde un lugar intermedio que no fuera ni oficial -como el Vera-, ni tan independiente -como El flotante o La Mariño. De esta manera, el galpón de diez metros por veinticinco, ubicado en el Pasaje céntrico Villanueva, cuenta con una capacidad para albergar a cien espectadores/as y funciona, desde entonces, con gran actividad.

Así, teniendo en cuenta algunos aspectos ligados al patrimonio arquitectónico teatral, a las diferentes salas y a recepción teatral de la ciudad de Corrientes capital se observa cómo el teatro se ha ido consolidando en infraestructura y ganando más espacios para la producción. Mientras tanto, por fuera de las salas, una vez al año, durante la fiesta de carnaval, resulta altamente significativo el público asistente que se reúne en las tribunas y calles de la ciudad para disfrutar rigurosamente de los shows de comparsas, concurrencia que logra superar los números de cualquier función teatral realizada durante el año. Eminentemente teatral, estos shows logran manifestarse como auténticas puestas en escena, aun cuando su realización exceda al campo específico.

Hasta aquí la primera entrega del trabajo de investigación. En la segunda parte nos abocaremos a otros aspectos del teatro correntino: el teatro realizado dentro de la provincia (en la ciudad de Goya, Monte Caseros y de Paso de los Libres); aspectos de la dramaturgia regional; el lugar que ha tenido la investigación teatral en la zona y el análisis sobre una puesta en escena contemporánea. 


\section{Dibliografía}

» A.A.V.V. (1990). “La historia de Corrientes en los Estudios sociales regionalizados (Primera Parte)" en Guía de Estudios y actividades del Instituto Regional de Estudio Superiores, Prof. Eduardo Rial Seijo, Corrientes: Amerindia Ediciones Correntinas.

"Benítez, l. “Taka” (2009). Entrevista personal realizada por la autora.

» Busciglio, L. (2009). Entrevista personal realizada por la autora, Corrientes.

»De Paris, M. (1988). Corrientes y el santoral profano. Buenos Aires: Plus Ultra.

»Fernández, M. D. (2009). Entrevista personal realizada por la autora, Corrientes.

» Fernández, M. D. (2007) El carnaval correntino: pasado y presente de una obra de arte en movimiento. Corrientes: Editorial Moglia.

» Fernández, M. D. (2005) Historia de la actividad teatral en la provincia de Corrientes. Buenos Aires: Instituto Nacional del Teatro. Colección El país teatral, serie Historia.

» Helfgot, M. (2005, 2 de octubre). “Corrientes. La provincia de las 17 intervenciones", Clarín.

》Leguiza, F. A. (2007) Carnaval en Paso de los Libres: desde sus orígenes hasta la década de 1930. Corrientes: Editorial Moglia.

"Pellettieri, O. (2003) Historia del teatro argentino en Buenos Aires: la segunda modernidad 1944-1976. Buenos Aires: Galerna.

»Pellettieri, O. (2001). "En torno al actor nacional: el circo, el cómico italiano y el naturalismo", en De Totó a Sandrini. Del cómico italiano al "actor nacional" argentino, Bs As: Galerna.

»Wybert, J. M. (2008/2009). Quién es quién en Corrientes. Corrientes: Sociedad Argentina de Escritores.

\section{Otros materiales de consulta}

》 (1977). "Corrientes: Dante Cena y los talleres de teatro" en Teatro NacionalUnidad informativa cultural de FATTA- Año 1 No. 3 y 4, p 11 y 12. Rosario: Editorial Amalevi.

» (2008). "Correntinas cautivas del teatro" Programa de mano de la XXVI Fiesta Provincial del Teatro, 4 al 6 de septiembre, Corrientes: INT

» (2008). "Teatro NEA" Programa de mano de la IX Fiesta Regional del Teatro NEA, 6 al 9 de noviembre, Corrientes: INT

"S/A (2000). "Teatro Contemporáneo. Grupo Ambaí, a la búsqueda del teatro que une" en Revista Macedonia, No. 27, agosto, P. 30-33. 